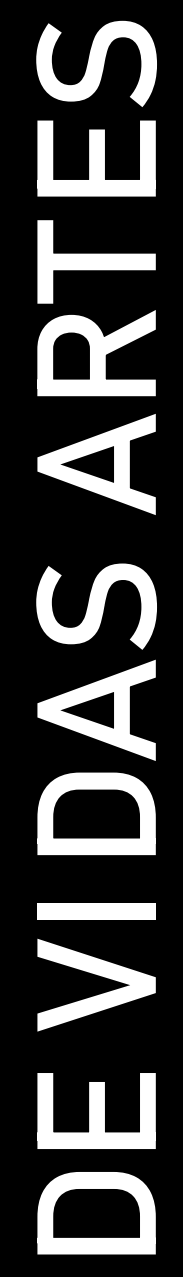

PAULA GUERRA E LÍGIA DABUL (EDS.) 


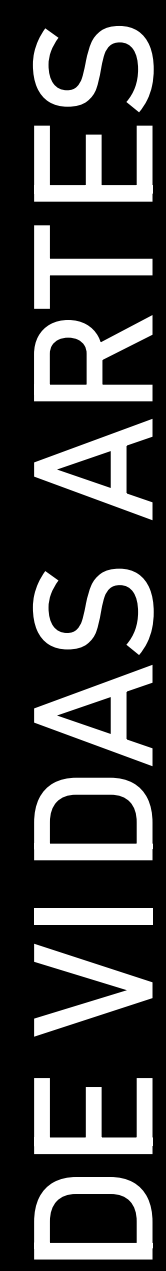

\section{PAULA GUERRA E LÍGIA DABUL (EDS.)}

Design por Irandina Afonso

Ilustração da Capa por Lua Celina

Publicado em Setembro 2019

Universidade do Porto. Faculdade de Letras

[University of Porto. Faculty of Arts and Humanities]

Porto, Portugal

ISBN 978-989-8969-18-7

Suporte: Eletrónico - Formato: PDF / PDF/A 


\title{
1.2. Da Arte de Vender Arte: Uma antropologia das galerias e galeristas brasileiros
}

\section{I.2. The art of selling art: An anthropology of Brazilian galleries and gallerists}

\section{Leonardo Bertolossi}

\section{Resumo}

O objetivo desse artigo é apresentar e analisar alguma antropologia das razões simbólicas que motivaram a vida das galerias e o ofício de galeristas no Brasil, assim como alguns episódios, personagens e aspectos fundamentais de suas histórias. $O$ texto destaca a biografia do mercado primário de arte contemporânea; as práticas sociais responsáveis pela iniciação e conversão de colecionadores em galeristas; a trajetória do colecionador e galerista Marcantonio Vilaça; e algumas das sociabilidades, polêmicas e performatividades presentes no mundo das galerias. 0 ensaio finaliza se indagando sobre o futuro da profissão dos galeristas e das obras de arte.

Palavras-chave: galeria, galerista, colecionismo, mercado de arte, arte contemporânea.

\begin{abstract}
This article aims to present and analyse some anthropology of symbolic reasons that motivate the life of galleries and the trade of gallerists in Brazil, as well as some fundamental episodes, characters and aspects of their histories. The text highlights the primary market of contemporary biography; the social practices responsible for the initiation and conversion of collectors into gallerists; the trajectory of the collector and gallerist Marcantonio Vilaça; and some of the sociabillities, controversies and performativities present in the world of galleries. The essay concludes inquiring the future of gallerists' profession and works of art.
\end{abstract}

Key words: gallery, gallerists, collectionism, art market, contemporary art.

"As utopias, afinal de contas, são, sobretudo, obras de arte." - Paulo Leminski

\section{Introdução: Deambulando entre galerias e galeristas}

Quando estava começando a construir o campo de pesquisa do doutorado sobre galerias e mercado de arte (Bertolossi, 2015), cometi uma gafe que se tornou reveladora do mundo dos galeristas, um anthropological blues nos termos de DaMatta (1978). Após trocar e-mails e ter um primeiro encontro 
com uma dada galerista ${ }^{28}$, a questionei onde nos encontraríamos novamente, se nas dependências da galeria ou na "loja". A reação calorosa de incômodo da galerista com o termo loja me fez perceber na prática o que Bourdieu (2004) já enunciara sobre a denegação do econômico nos rituais artísticos. Aprendi ali que galeristas não são "vendedores" e muito menos possuem "lojas": são difusores culturais, representantes de carreiras artísticas e promotores do amor à arte.

Um ano depois tive a oportunidade de encontrar outro galerista em sua singela galeria também localizada na Vila Madalena - bairro que ao lado dos Jardins abriga ainda hoje as mais poderosas galerias do país - e me recordo de seu mal-estar com o fato de que, segundo ele, o mercado das galerias estava se tornando uma "corrida de cavalo". Se no passado as galerias eram habitadas por indivíduos interessados na sociabilidade artística, no cultivo e na troca diante das obras e da presença de artistas, o campo agora havia se tornado acelerado e envolvido em jantares, estratégias de otimização de vendas, uma profusão desenfreada de commodities, feiras e artistas cuja produção era informada pelas intensas demandas de mercado.

Ainda em minhas deambulações pelo campo encontrei um pioneiro galerista, já falecido, importante personagem, sobretudo pela projeção dos artistas da chamada geração 80; e também outra personagem sênior, cuja galeria já possui quarenta anos de estrada representando artistas consagrados e tendo sido considerada uma das galerias mais importantes da América Latina pela revista Artforum. Esse galerista sênior me afirmara que um artista ambicioso deveria se dedicar integralmente ao ofício - e esse foi um dos motivos de seu desentendimento com uma de suas artistas quando ela engravidou. De acordo com ambos, tudo era mais rudimentar no começo, sem a existência da Internet e com todas as atividades sendo realizadas com parâmetros mais subjetivos e menos padronizados.

O que aproxima esses diferentes relatos e pessoas? O controverso amor pela arte. Ainda que o mercado de arte internacional seja um dos setores mais rentáveis por décadas, com poucos períodos de crise

\footnotetext{
${ }^{28}$ Em consideração e respeito aos meus interlocutores no campo preferi não mencionar explicitamente o nome de galeristas e artistas envolvidos em histórias pessoais ou polêmicas quando não obtive autorização para fazê-lo. Desse modo, as memórias e referências aqui evocadas apresentam relatos que julgo importantes para uma história e antropologia das galerias e dos galeristas, com o cuidado ético de não expô-los a constrangimentos. As demais informações presentes nesse artigo estão públicas e foram encontradas em artigos científicos, revista e catálogos de arte e em periódicos.
} 
sobrevivendo às diversas ondas do capitalismo; essas pessoas, dentre outras que gravitam esse universo como artistas, colecionadores, críticos, curadores e o público defendem que não se trata do gosto pelo dinheiro, que poderia ser obtido em outros ramos profissionais ou através do comércio de outros produtos de luxo, mas dos afetos envolvidos nos mais diversos significados em circulação nesse mundo. Falar de mercado de arte e de galeristas ${ }^{29}$ é, portanto, falar de uma economia moral dos afetos que transcende a mera esfera do econômico e do monetário.

Sendo assim, o objetivo desse ensaio é apresentar alguma antropologia das razões simbólicas que motivam a vida e o ofício de galeristas do mercado primário no país, assim como alguns episódios, personagens e aspectos fundamentais de sua história.

\section{Alguma biografia do mercado}

Talvez seja possível dizer que "tudo começou" quando a arte moderna já devidamente emancipada das obrigações e subvenções da Igreja e do Estado começa a produzir a persona do gênio - essa herança conceitual romântica - com trabalho autoral. Jorge Coli (2010) identifica já em Courbet as características do que foi chamado de artista moderno, sobretudo no que tange à subversão das convenções, o culto à personalidade e a defesa de um trabalho autônomo e livre. A arte se tornava um problema, uma equação a ser resolvida no suporte, conforme nos sugere Merleau-Ponty (2004), ao falar de Cézanne, outro "pai" da modernidade vanguardista.

O culto ao novo fez os artistas modernos reencontrarem a originalidade no originário e muitos vanguardistas flertariam com a antropologia e seu interesse pelos povos ditos primitivos. Muitas vezes "párias" das metrópoles insurgentes, tais artistas foram subsidiados pelo mecenato dos primeiros galeristas, àquela altura ainda chamados de marchands, como Paul-Durand Ruel, Daniel-Henry Kahnweiler e Ambroise Vollard - que representavam artistas impressionistas e nabis -, e Theo Van Gogh - irmão e marchand que apoiou Vincent Van Gogh ao longo de sua breve vida.

\footnotetext{
29 É importante destacar que as temáticas e questões assinaladas nesse texto se referem ao mercado primário de arte contemporânea, que é aquele que faz a primeira venda e realiza a representação profissional de um dado naipe de artistas. Já o mercado secundário é responsável pela realização de revenda de obras de arte, o que contempla as galerias de revenda e os leilões. Os valores obtidos pelo mercado primário informam práticas e políticas de venda do mercado secundário, assim como os números alcançados em leilões também informam e orientam as estratégias do mercado primário.
} 
De acordo com Maria Lúcia Bueno (2005), após a segunda guerra mundial as galerias da cidade de Paris, bastante fragilizadas, venderam grande parte do seu acervo para os Estados Unidos. A arte pop americana e o expressionismo abstrato afirmaram e consolidaram a nova posição de destaque do mundo americano no campo internacional das artes visuais, e Nova York se tornara a nova Meca de galerias no planeta, posição que persiste até a atualidade. Nesse contexto dois nomes teriam destaque: Leo Castelli, representante de Andy Warhol, e Peggy Guggenheim, poderosa marchand que estava à frente da Art of the Century, a galeria mais importante do período, responsável pela projeção estrondosa de artistas como Alexander Calder.

No Brasil já existiam algumas poucas galerias no início do século em São Paulo e no Rio de Janeiro. Naquela altura, conforme relata Bueno (2005), eram pequenas lojas de móveis que vendiam quadros e algumas esculturas para as elites locais interessadas em artes. No Rio de Janeiro havia uma pequena galeria chamada Jorge, aberta em 1907 e localizada na rua do Rosário; e em São Paulo, existia a galeria Itá, aberta em 1939, que era frequentada pelos modernistas, dentre eles Mário de Andrade. Pode-se dizer que o mercado primário de arte brasileiro começa a despontar efetivamente a partir dos anos $1950 \mathrm{com}$ a chegada de imigrantes que se tornaram a primeira geração de galeristas. Nomes como Jean Boghici, Franco Terranova, Giuseppe Baccaro, Paolo Businco, Pietro Bo Bardi e Thomas Cohn advinham de setores bastante distintos como o mercado exterior, como Cohn, ou mesmo profissionais liberais como Boghici, que havia atuado anteriormente como vitrinista e eletricista, respetivamente. Todos eles, no entanto, eram colecionadores antes de começarem a representar artistas em suas galerias.

Celso Fioravante (2001) afirma que alguns patronos das artes visuais também possuíam suas próprias galerias. Pietro Bo Bardi, responsável pela criação do Museu de Arte de São Paulo com o colecionador Assis Chateaubriand, um dos maiores equipamentos culturais do país, e Cicillo Matarazzo, mecenas do Museu de Arte Moderna de São Paulo, tinham suas galerias próprias, como a Mirante das Artes de Bo Bardi por exemplo. Arturo Porfirio, por sua vez, trabalhava como secretário geral na ainda incipiente Bienal de São Paulo, aberta em 1951, e em sua galeria Sistina aberta em 1958 na cidade. Até mesmo o grupo Globo de comunicações possuía sua própria galeria, a Arte Global, localizada na cidade do Rio de Janeiro e tendo 
Franco Terranova como seu diretor. Esses exemplos são elucidativos de como as fronteiras entre circuito artístico e mercado de arte eram frágeis nessas primeiras décadas de afirmação e constituição do campo, uma relação tornada ainda mais interdependente na atualidade.

José Carlos Durand (1990) e Maria Lúcia Bueno (2005) sugerem que o mercado consumidor de obras de arte até meados dos anos 1970 era basicamente constituído por estrangeiros residentes no país. Parte desse patrimônio era compartilhado por poucas famílias tradicionais de São Paulo e do Rio de Janeiro e era prática comum as obras serem emprestadas e circularem entre coleções das mesmas. O "colecionador brasileiro" só teria surgido de forma expressiva no contexto do milagre econômico, personagem que ganharia expressão, sobretudo após a abertura política e com o "boom" de galerias dos anos 1980 em decorrência da redescoberta da pintura e da invenção da geração 80 .

Para Ricardo Basbaum (2010), a geração 80 nunca existiu por si própria, tendo sido fabricada através de um consórcio entre os galeristas, a mídia impressa à época e o novo personagem proeminente do campo: o curador de exposições. Os artistas que compuseram a tal geração eram muitos e seus trabalhos muito diferentes entre si, tendo sido agrupados através de um clichê/estereótipo de mercado por representarem um vago espectro de artistas entusiasmados com a retomada internacional da pintura. Muitos desses artistas eram muito jovens, em torno de vinte anos de idade, e fizeram sua formação na Fundação Armando Alvares Penteado e na Escola de Artes Visuais do Parque Lage, recém aberta após o incêndio do Museu de Arte Moderna-Rio. Alguns deles são hoje nomes de ponta do país no exterior, dentre eles, Adriana Varejão, Beatriz Milhazes, Ernesto Neto, Leda Catunda e Nuno Ramos.

Se o Rio de Janeiro foi pioneiro ao afirmar galerias importantes como a Petite - aberta em 1953 pelo pintor Mario Agostinelli - e a Saramenha inaugurada em 1977 pelo artista Victor Arruda e seu irmão - São Paulo despontaria como protagonista no mercado a partir da metade dos anos 1980 e em especial nos anos 1990, sobretudo após a ida de Thomas Cohn para a cidade e a chegada de novos personagens como o pernambucano Marcantonio Vilaça. É também nos anos 1990 que algumas galerias de Belo Horizonte e de Curitiba surgem no mercado ainda bastante centralizado do 
eixo Rio-São Paulo, assim como alguns colecionadores e curadores começam a promover a produção artística realizada no Nordeste do país.

\section{Tornar-se galerista}

Se hoje cada vez mais a ideia de tornar-se galerista parece uma alternativa promissora a jovens interessados em representar artistas e viver diante dos rituais do mundo da arte, antes a profissão era bastante restrita a iniciados que eram, por sua vez, consagrados através de relações de convívio e aprendizado íntimo com colegas sêniores. Desse modo, é possível evocar a importância do trabalho desenvolvido pelo galerista Giuseppe Baccaro ao seu sucessor, Ralph Baccaro. Certamente o trabalho do marchand Franco Terranova, um dos mais importantes nomes da história do mercado brasileiro, foi fundamental para a galerista Raquel Arnaud, cuja galeria já celebra seus quarenta anos, e tendo com ele começado. Por fim, à guisa de mais um exemplo possível, sem dúvida a amizade entre a jornalista Márcia Fortes e o colecionador e art dealer Marcantonio Vilaça foi importante para que Márcia se consolidasse como um dos nomes mais fortes do mercado após a morte do sócio e amigo, posição que mantém, por sua vez, até a atualidade.

Conforme mencionei anteriormente, realizei entrevistas com galeristas durante a pesquisa da tese e pude notar que galeristas não se veem como vendedores de obras de arte tão somente. Ao contrário, se entendem como produtores culturais e representantes de trajetórias e expressões artísticas que permitem aos seus interessados se tornarem melhores pessoas no mundo, indivíduos cultivados e partícipes de uma comunidade "espiritual" de pensamento através das formas e poéticas em circulação produzidas pelos artistas e em exibição nas galerias, museus e nos acervos pessoais de colecionadores.

Fazer parte desse seleto grupo exige o aprendizado de algumas qualidades intrínsecas e irrevogáveis, sobretudo àqueles que pretendem se tornar galeristas. Muitos galeristas me afirmaram frequentar o ateliê de seus artistas com regularidade e debater com os mesmos as direções que 0 trabalho irá tomar a partir da interseção entre os interesses poéticos e políticos do artista e as demandas do mercado. A frequentação intensa em exposições nos principais museus nacionais e internacionais, assim como a presença regular de suas galerias em feiras, é parte fundamental do ofício, e 
aquele que se pretende galerista deve incorporar tais práticas em seu cotidiano profissional.

A participação em feiras de prestígio garante o reconhecimento do galerista entre os seus pares, sobretudo se além de participar das feiras como expositor o mesmo começa a integrá-la em seu comitê. Além disso, a presença em uma dada feira renomada é fundamental para que o galerista consiga acessar outras do mesmo quilate, o que ocorre muita das vezes através da indicação dos seus colegas. Esse é o caso da entrada de uma dada galerista na Art Cologne por indicação de seu colega, uma das feiras mais tradicionais do mercado internacional e aberta em 1967. Tal galerista, anos mais tarde, viria a indicar o nome desse colega para a Art Basel Miami, mas um incidente fez com que o mesmo fosse convidado a se retirar do evento. Por ocasião do Nine Eleven, o colega sugeriu que a feira fosse cancelada e evocou o nome da galerista como partícipe do pleito de fechamento do evento. Conforme ambos me relataram em entrevistas, a galerista negou o envolvimento com o pedido do colega, o que produziu constrangimento e o pedido de seu afastamento, prejudicando sua reputação e dificultando sua entrada em outras feiras internacionais.

Se hoje o mundo se tornou "encurtado" através da Internet, das redes sociais e das mídias digitais, nesse alvorecer do mercado primário de arte contemporâneo após a ditadura, era mister que galeristas viajassem frequentemente para se atualizar acerca das novas tendências e expressões do campo. Essa frequentação intensiva era necessária para a produção do olho, categoria recorrente na retórica dos art dealers, que se entendem como responsáveis por produzirem descobertas ainda inóspitas no mercado, uma profissão de fé de revelar artistas potenciais como profecia de sucesso e afirmação profissional de suas trajetórias.

Cabe aos galeristas iniciar no mundo da arte àqueles que têm a pretensão de se tornar parte do mesmo. Conforme afirma a antropóloga Dayana de Cordova (2017), muitos colecionadores têm o seu turning point após sucessivas idas às feiras e galerias deixando de ser meros "acumuladores" e concebendo uma assinatura identitária pessoal para as obras que passam a adquirir. A constituição desse habitus se dá em grande parte pelas investidas e pela educação dos sentidos decorrente da amizade com galeristas, muitos deles também colecionadores de arte. 
Muitos galeristas afirmam estarem suprindo uma demanda existente e que deveria ser realizada pelos equipamentos culturais das grandes capitais. Alguns dos nomes que entrevistei afirmavam que museus de arte estão desaparelhados, fragilizados, e não possuem uma política de aquisição de obras, muitas delas em empréstimo nessas instituições através de comodato. Desse modo, art dealers entendem fazer o trabalho de projeção de carreiras que caberia às instituições artísticas, enquanto que diretores artísticos/curadores de museus afirmam que as ações de galeristas são todas motivadas pelas ansiedades de mercado. O mais interessante nessa disputa retórica pelo protagonismo artístico entre curadores e galeristas é que ambos atuam muitas das vezes em conjunto, já que é comum a prática de venda diferenciada e concessão de obras de artistas para coleções importantes de modo a valorizá-las no mercado, assim como muitos galeristas - como foi o caso de Marcantonio Vilaça - atuam como consultores de diretores artísticos para a escolha de artistas para suas exposições.

Galerias escolhem clientes potenciais que poderão projetar a carreira dos artistas, manter os valores e preços construídos e em monitoramento no mercado. Esses valores são informados em grande parte pelo currículo do artista, pelas mostras que participou e coleções que integra, mas também por valores alçados em leilões. É comum galeristas flexibilizarem e facilitarem a compra para professores universitários, para outros artistas (que costumam trocar obras entre si) e pessoas com capital intelectual e social compatível com a comunidade de bens artísticos que constitui esse universo. Outra característica fundamental de galeristas exitosos é o seu carisma, traduzido pela capacidade de articular e fazer gravitar ao seu redor diferentes artistas e públicos potenciais colecionadores. Tal prestígio e centralidade é tão grande que muitas galerias brasileiras acabam por fechar após a morte dos seus representantes (especialistas estimam em até três anos), o que tem feito com que muitas galerias atualmente realizem uma gestão mais horizontal com uma equipe de dealers ao invés do protagonismo de um único indivíduo.

\section{Marcantonio Vilaça}

Sem dúvida, um dos nomes mais importantes do mercado de arte brasileiro é o do pernambucano Marcantonio Vilaça e por esse motivo pretendo apresentar e discutir alguns aspectos de sua trajetória singular. Marcantonio integra um time de nomes importantes da Velha Guarda como os de Jean Boghici, Franco Terranova, Luisa Strina e Raquel Arnaud. O colecionador, 
que se tornou marchand nos anos 1990, é conhecido como um dos principais responsáveis pela projeção de artistas contemporâneos brasileiros da geração 80 e dos anos 1990 no mercado internacional.

Marcantonio advém de uma aristrocracia pernambucana, tendo sido filho de ex-Ministro do Tribunal das Contas da União e membro da Academia Brasileira de Letras, oriundo de uma família que possuía uma algodoeira importante em Recife. Formado em Direito, o colecionador resolveu migrar para São Paulo, onde seu interesse por arte pode ser vivenciado com mais intensidade. Nas memórias do personagem consta que ele ganhou uma gravura do artista Samico, tendo sido a primeira obra de sua coleção.

A memória de Vilaça, falecido na madrugada do Réveillon do ano 2000 por um ataque cardíaco, é atravessada por histórias polêmicas e elogiosas. Quando se trata de Marcantonio Vilaça não há meio termo - ou ele era amado e idolatrado por seus seguidores, ou detestado por seus muitos inimigos. As contradições e ambiguidades em torno da personagem são bastante enriquecedoras para pensar a lógica de funcionamento de um campo pautado por alianças pessoais, afetos interessados, controle social através de rumores e etiquetas, e muita distinção social.

Antes de abrir em 1992 a famosa galeria que consagraria o seu nome na Vila Madalena, em São Paulo, a Fortes Vilaça, Marcantonio representou artistas pernambucanos na Pasárgada, inaugurada no final dos anos 1980, galeria que administrava com sua irmã em Recife. Vilaça realizou um intenso intercâmbio cultural entre o Nordeste e o eixo Rio-São Paulo, tendo levado artistas considerados "periféricos" para o centro e apresentado artistas paulistas em sua galeria em Recife, produzindo muito dissabor e ciúme entre os artistas dessa cidade. Sintonizado com a retomada da pintura na arte brasileira nos anos 1980 e 1990, Marcantonio representou artistas hoje consagrados como Beatriz Milhazes e Adriana Varejão, mas também agregou em seu time nomes que dialogavam com 0 conceitualismo das neovanguardas das décadas anteriores, como Jac Leirner.

Alguns artistas me contaram em entrevista que o galerista possuía uma relação bastante passional com eles, muitas das vezes relegando-os a um certo lugar marginal temporário no mercado após conflitos, como foi o caso de um proeminente artista carioca. Ao entrevistar esse artista em seu ateliê, ele me relatou que amigos comuns a ambos interferiram para mediar 
uma trégua e reconciliação, como foi o caso de um importante colecionador e editor. Ou, num tom contrário, era extremamente bem humorado e afetuoso com seus artistas prediletos, como me afirmou uma artista de São Paulo, que dele recebia ligações entusiasmadas para comentar o crescimento de seus nomes no mercado.

Moacir dos Anjos (2006) afirma que Marcantonio tinha a jovialidade, a curiosidade e a energia para estar em constante movimento, ao contrário de seus colegas galeristas que possuíam em grande parte uma idade bastante avançada em comparação a ele. Numa época em que não havia o tempo real do mundo digital e as informações eram trocadas por telefone, fax e telegrama, ele estava sempre viajando e frequentando feiras e bienais não apenas nos Estados Unidos e na Europa, mas também na América Latina. Um dos trunfos do galerista foi antever a importância da arte latino-americana e fazê-la circular entre seus pares quando todos a consideravam algo "cucaracha". E ele viveu isso num momento em que havia uma crescente demanda pela produção de fora do mundo euroamericano em exposições emblemáticas como a Bienal de Havana de 1986 e a exposição Magiciens de la Terre, no Centro Georges Pompidou em Paris, em 1989.

O galerista foi responsável também pela iniciativa de abrir a revista Galeria, uma publicação totalmente voltada para o mercado de arte contemporânea e a divulgação da produção de novos artistas com textos críticos escritos por curadores hoje renomados. Posteriormente ele se afastaria da revista por ter sua própria galeria, mas o fato é que esse veículo foi fundamental num momento em que, segundo a antropóloga Fernanda Peixoto (2000), o mercado editorial em artes visuais no país ainda era muito insipiente e existiam poucas iniciativas nesse sentido, parte delas realizada por artistas, como as revistas Malasartes e A Parte do Fogo, publicadas anteriormente. Marcantonio também fazia parte da comissão de diversas feiras, como a ARCO Madrid, e foi um dos pioneiros a facilitar formas de pagamento para seus colecionadores, permitindo a realização de compras a prazo e com parcelamentos. O galerista teve uma vida breve, mas intensa. Ao perguntar para uma grande amiga galerista o motivo de sua morte ela foi categórica: "morreu de galeria". De acordo com ela, Vilaça estava doente e trabalhando intensamente antes do sinistro.

Após o falecimento o personagem foi homenageado de diversas formas, dentre elas, dando o nome para dois prêmios importantes, o Prêmio 
de Artes Plásticas Marcantonio Vilaça da FUNARTE, e o Prêmio CNI SESI Marcantonio Vilaça que dão suporte a novos criadores. Além de Jac Leirner, outros artistas brasileiros entrevistados me relataram em entrevista 0 reconhecimento internacional do galerista por colegas estrangeiros como Jay Jopling, da galeria White Cube, dentre outros nomes como Olga Viso, Rosa de la Cruz e o galerista português José Mário Brandão, todos interessados em arte brasileira através do agenciamento realizado por Vilaça.

\section{Sociabilidade, polêmica e performatividade em galerias}

Gostaria de me ater agora ao cenário das galerias propriamente. Olav Velthuis (2005) escreveu sobre a arquitetura das mesmas e nelas identificou uma hierarquia de valor nos espaços. Na parte principal, o showroom, há o clássico cubo branco onde as obras estão em exibição, lugar em que as pessoas sociabilizam por ocasião da abertura das mostras, sítio onde acontecem palestras e eventualmente cursos. O curioso é que o preço dos trabalhos artísticos nunca está indicado, afinal, ainda que as galerias sejam espaços comerciais, toda a retórica do campo desloca esse aspecto fundamental para o segundo plano. E é no price room, na sala onde está o escritório do galerista, que as coisas acontecem. Ali, na mesa do galerista, que quando o potencial cliente colecionador se senta, terá acesso aos valores reais das obras e às condições possíveis de pagamento e de financiamento.

Muitos desses clientes já vão à galeria informados sobre as obras de arte do seu interesse. No começo da pesquisa do doutorado, realizei em 2010 um breve campo em uma das maiores galerias do mercado, na Vila Madalena, onde pude ter acesso a algumas das estratégias de divulgação e sedução de clientes potenciais. Além do contato telefônico, é prática recorrente o envio dos "pacotes", termo nativo, que constam de um malote de informações para o potencial comprador, dentre elas, catálogos do artista, uma seleção de reportagens e clippings sobre o seu trabalho em periódicos nacionais e internacionais de relevo, o currículo atualizado do artista com as exposições que participou, e por fim, o que nos parece hoje algo obsoleto, um CD-ROM com imagens dos trabalhos em alta definição.

As aberturas de exposições individuais e/ou coletivas e de feiras de arte são um ritual à parte. É onde se autocongratula o "clube dos eleitos", a grande sociedade de corte que é o mundo da arte. Artistas, colecionadores, curadores, amigos de artistas e interessados em artes visuais se encontram 
ali e sociabilizam, atualizando os afetos e as razões simbólicas que orientam sua frequentação nesses ambientes. É onde também, ao lado das redes sociais como o instagram, os laços profissionais são construídos e mantidos, espaço em que há a possibilidade de surgirem convites e parcerias inusitadas. E, para os players do campo, lugar para ficar atento ao que está em alta e saber quais são as orientações do mercado no momento. Segundo o sociólogo Guilherme Marcondes (2014), frequentar vernissages e feiras é fundamental para existir nesse campo, é o espaço ritual do ver e ser visto, construir sua existência social num universo pautado pela capitalização da exibição e representação de si e de obras artísticas. E como sugere Goffman (2005), é necessário saber performatizar e sustentar a fachada ideal que mantenha o potencial expressivo diante dos outros atores do campo.

Galerias também são palco de polêmicas, experimentações e ações estético-políticas na história do campo das artes visuais. Dentre muitas histórias possíveis, gostaria de destacar três emblemáticas da inserção do ambiente das galerias brasileiras na constituição do circuito, a saber: a polêmica envolvendo os leilões forjados pelo galerista Paolo Businco na Collectio; a mostra-happening "Exposição Não-Exposição" realizada por Wesley Duke Lee, Nelson Leirner e o seu grupo REX por ocasião do encerramento desse coletivo; e a performance do grupo A Moreninha, encabeçado pelo artista Ricardo Basbaum, na galeria Saramenha por ocasião da palestra do crítico de arte Achile Bonito Oliva.

Segundo Celso Fioravante (2001), em plena ditadura civil-militar, o imigrante italiano foragido, Paolo Businco, forjou uma identidade falsa e abriu a galeria Collectio, em 1969, realizando leilões que desregularam os preços do mercado. Businco fora desmascarado como estelionatário por realizar vendas fictícias com documentos falsos, compradores laranjas e por oferecer obras de arte como garantias de empréstimos aos bancos da cidade. Após o escândalo da lavagem de dinheiro da Collectio o mercado de arte ficou completamente desestabilizado e demorou alguns anos para se recuperar.

Ainda sobre esse controvertido episódio, Sergio Miceli (2002) afirma que os leilões dos italianos Giuseppe Baccaro e Paolo Businco eram os principais referenciais do mercado, cujas obras eram em grande parte adquiridas por colecionadores de ascendência judaica. José Paulo Domingues foi o nome usado por Businco, ex-advogado e ex-empresário falido, para forjar sua identidade falsa, quando obteve financiamento dos seus 
leilões de linhas especiais de crédito bancário. A atuação de Businco foi concomitante a um momento de surto especulativo na bolsa de valores. Após sua queda e a revelação do estelionato, Businco faleceu de forma súbita e controvertida em 1973, tendo deixado diversas dívidas decorrentes de transações suspeitas.

Sobre o episódio envolvendo o grupo REX, nos anos 60, o artista concretista Wesley Duke Lee, que depois se casaria com a galerista Luisa Strina, abriu a galeria REX Gallery \& Sons, com o mesmo nome do grupo que a coordenava, mas funcionava como uma cooperativa de artistas críticos ao mercado e à falta de espaços para as vanguardas naquele momento. Duke Lee lançou ainda o periódico Rex Time, veículo impresso que durou três anos. O evento em questão, tido como um dos mais marcantes daquele momento e que objetivava proferir uma crítica radical ao estatuto da arte como mercadoria de uma elite industrial e mercantil cultivada e elitizada, foi o happening "Exposição-Não Exposição", encabeçado por Nelson Leirner, e que consistia na inauguração de uma exposição na galeria REX.

Nessa suposta "vernissage" que o grupo inventou para encerrar suas atividades, os visitantes poderiam levar para suas casas as obras gratuitamente, desde que conseguissem arrancá-las com marretadas das paredes onde estavam chumbadas e acorrentadas. O público à porta da galeria, localizada na Faria Lima em São Paulo, estava ansioso por esse momento e ao adentrar o recinto levou as obras em apenas oito minutos. Boa parte dos trabalhos foram posteriormente vendidos na porta da galeria e a polícia chegaria logo depois para dissipar a multidão e finalizar as atividades do evento.

Anos mais tarde, outro ato performativo marcaria a história da arte brasileira através da atuação do coletivo A Moreninha em uma galeria. Em 1987 o grupo realizou uma polêmica intervenção na palestra do badalado curador e crítico italiano Achille Bonito Oliva, teórico da transvanguarda italiana. A palestra aconteceu na galeria Saramenha, cujo proprietário era o artista Victor Arruda, e ficava localizada dentro do shopping da Gávea, uma das mais expressivas do mercado carioca naquela altura. Ivair Reinaldim (2013) comenta que o intuito de Oliva era divulgar seu novo projeto teóricoartístico, o Progetto Doce, espécie de variação da transvanguarda internacional. Nessa ocasião também estava acontecendo uma exposição 
individual da artista italiana Paola Fonticoli na mesma galeria, cuja obra estava totalmente influenciada pelas tendências daquele momento.

Basbaum e o grupo de artistas a ele vinculado, como Alexandre Dacosta, Jorge Barrão, Márcia Lemos e Lucia Beatriz, adentraram a palestra vestidos como garçons distribuindo torrões de açúcar e balas, orelhas de burro e imagens de São Cosme e Damião. Alguns artistas, amigos do grupo e que estavam informados da performance, vestiram as orelhas de burro. Já outros, como Enéas Valle, assistiram toda a palestra de costas vendo a apresentação do teórico italiano através de um espelho. Um dos artistas trazia um gravador que tocava o sucesso da dupla de música sertaneja Pirapó e Cambará misturadas com narrações de trechos do filósofo pré-socrático Heráclito.

Resultado: o crítico, que estava informado de que haveria uma performance e sinalizado de que a mesma deveria acontecer antes ou depois de sua palestra, ao perceber a "invasão" imprevista dos artistas, ruborizou-se, aborreceu-se, atacou a performance e agrediu um dos artistas, arremessando o seu gravador no chão. Hilton Berredo afirma ter ouvido palavras desaforadas do crítico, que o julgou idealizador de toda a ação, e terminou por dar um banho de uísque em Achille Bonito Oliva, que disparou o copo na parede da galeria. Após a revolta do crítico, o grupo debandou para fora gritando: "Moreninha, Moreninha!".

Achile Bonito Oliva julgou a performance como expressão de um gesto ufanista-nacionalista e xenófobo, disparou duras palavras à crítica de arte brasileira, que julgava provinciana e medíocre após a morte de Mário Pedrosa. Pior ainda, afirmou que a cultura brasileira era "sambista" e que a produção artística daqui era atrasada e folclórica. Chamou ainda aos nossos artistas de "replicantes" copistas dos modelos internacionais, tendo usado o nome do prestigiado Rubens Gerchman, um dos "pais" da Escola de Artes Visuais do Parque Lage, que reagiu veemente às críticas.

\section{Considerações Finais: Arte, commodities e utopia}

Iniciei esse artigo mencionando a gafe que cometi no campo ao chamar uma prestigiosa galeria de "loja", e finalizo agora evocando a exaltação de uma pioneira art dealer ao me dizer com muita veemência "que o mundo dos galeristas era de zero glamour e de muito trabalho". O que tendemos a 
concordar se considerarmos o amadurecimento, consolidação do campo e o crescimento do número de galerias no país, assim como de feiras e bienais nacionais e internacionais.

De acordo com o projeto de pesquisa setorial Latitude, que analisa o desenvolvimento do mercado de arte brasileiro, o relatório de 2014 (3a․ edição), realizado sob coordenação da pesquisadora Ana Letícia Fialho (2014), mostra que a partir de 2010 até 2012 das quarenta e cinco galerias do mercado primário que participaram da pesquisa, $22 \%$ registraram aumento no volume de negócios. Em 2013 o índice aumentou para 27,5\%. O relatório identifica o melhor posicionamento das galerias no mercado internacional, assim como o crescimento do número de colecionadores. As galerias, por sua vez, aumentaram os seus quadros profissionais e as do mercado secundário, que operam com obras de artistas já consagrados, aumentaram suas vendas para o Exterior.

Talvez o galerista da Vila Madalena estivesse certo ao afirmar que o mercado de arte brasileiro se tornou uma "corrida de cavalo" quando o entrevistei. A imagem do marchand cultivado, homem erudito e aristocrático às voltas com o convívio espiritualizado das obras de arte e dos artistas é cada vez mais substituída pela persona do alto executivo cosmopolita e sintonizado com os índices e orientações do mercado de arte internacional em suas diversas frentes transnacionais, atendendo a uma demanda intermitente cuja agenda está previamente planejada com bastante antecedência. E é nesse contexto que surge em 2007 a Associação Brasileira de Arte Contemporânea, a ABACT, que afirma ter como missão promover a desburocratização e a profissionalização do setor, valorizando as diferentes etapas de produção e os seus responsáveis.

Mas a questão que não quer calar é: e o estatuto das obras de arte nesse contexto? Concomitante ao crescimento desenfreado do campo que sobrevive às diversas crises econômicas das grandes nações que 0 suportam, e ainda da transformação das obras de arte em algo correlato aos commodities que sustentam essa economia, estão as ações e expressões artísticas, cada vez mais mercantilizadas. Performances, site specific, street art, arte efêmera e desmaterializada têm sido registradas e traduzidas de modo a reinventar e alimentar o campo e o ofício dos galeristas, que dividem seus lucros com os artistas sob sua representação, que por sua vez produzem de modo a atender às crescentes demandas. 
Ao lado do crescimento do setor, há a incorporação pelo mundo das artes visuais do debate em torno de se repensar uma alternativa ao capitalismo mundial que permita à espécie humana sobreviver futuramente no planeta diante da iminência de catástrofes e pragas decorrentes do aquecimento global. O campo debate ainda e canibaliza a agenda decolonial e de representação de grupos minoritários e marginais alijados historicamente e ainda bastante desiguais no que se refere aos seus direitos. No entanto, a representação partida das sobras, de que fala Rancière (2005), ainda se dá apenas no âmbito do simbólico.

Teóricos e historiadores do campo, como Belting (2012) e Danto (2006), reinventam as proclamações de morte da arte, da aura, do objeto artístico, da noção de obra e de artista, mas como vimos, o mercado continua com todo vigor. Diante dessas inquietações que não são nem tão novas assim se considerarmos o pensamento sobre o futuro da arte em Benjamin (como jogo e política) e em Adorno (como indústria cultural), restam dúvidas sobre os desdobramentos futuros da profissão de galerista e do estatuto mesmo das obras de arte, ainda nesse campo do colecionismo às voltas com a materialidade, o consumo e o acúmulo de tais objetos de poder.

\section{Referências Bibliográficas}

Anjos, M. dos (org.) (2006). Invenção de mundos: Coleção Marcantonio Vilaça. Rio de Janeiro: Imago Escritório de Arte.

Basbaum, R. (2010). Pintura dos Anos 80: Algumas observações críticas. In Canongia, L.. Anos 80: Embates de uma geração (pp. 224-233). Rio de Janeiro: Barléu Edições.

Belting, H. (2012). O fim da história da arte. São Paulo: Cosac Naify.

Bertolossi, L. (2015). Arte enquadrada e gambiarra: Identidade, circuito e mercado de arte no Brasil (Anos 80 e 90). Tese (Doutorado). São Paulo: Universidade de São Paulo.

Bourdieu, P. (2004). A produção da crença: contribuição para uma economia dos bens simbólicos. São Paulo: Zouk.

Bueno, M. L. B. (2005). O mercado de arte de galerias e o comércio de arte moderna: São Paulo e Rio de Janeiro nos Anos 1950-1960. Sociedade e Estado, Vol. 20, No. 2, pp. 377-402.

Coli, J. (2010). O corpo da liberdade: Reflexões sobre a pintura do século XIX. São Paulo: Cosac \& Naify.

Cordova, D. Z. de (2017). Colecionadores, coleções particulares e o mercado brasileiro de arte contemporânea. OuvirOuver: Revista dos Programas de Pós-Graduação do 
Instituto de Arte da Universidade Federal de Uberlândia, Vol. 13, No. 2, Jul./Dez. 2017, pp. 468-479.

Damatta, R. (1978). O ofício do etnólogo ou como ter anthropological blues. Boletim do Museu Nacional, No. 27, Maio, pp. 1-12.

Danto, A. C. (2006). Após o fim da arte: A arte contemporânea e os limites da história. São Paulo: Odysseus Editora/EDUSP.

Durand, J. C. (1990). Mercado de arte e campo artístico em São Paulo, 1947-1980. Revista Brasileira de Ciências Sociais, São Paulo, Vol. 13, No. 13, pp. 101-111.

Fialho, A. L. (2014). Pesquisa setorial: O mercado de arte contemporânea no Brasil. $3^{a}$. Edição. Acesso em 5 de abril de 2019. Disponível em: http://latitudebrasil.org/media/uploads/arquivos/arquivo/relatorio_por-1.pdf

Fioravante, C. (2001). O marchand, o artista e o mercado. In Arco das Rosas: O marchand como curador. Disponível no site do Fórum Permanente. Acesso em 5 de abril de 2019. http://www.forumpermanente.org/event_pres/exposicoes/artecontemporaneo-arco/artigos-relacionados/o-marchand-o-artista-e-o-mercado

Goffman, E. (2005). A representação do eu na vida cotidiana. Petrópolis: Vozes.

Merleau-Ponty, M. (2004). A dúvida de Cézanne. In O Olho e o Espírito (pp. 121-142). São Paulo: Cosac \& Naify.

Miceli, S. (2002). Mercado de Arte: Brasil 2000. In Marques, Reinaldo; Vilela, Lúcia Helena (orgs.). Valores: Arte, mercado, política (pp. 79-105). Belo Horizonte: Editora UFMG/Abralic.

Peixoto, F. (2000). Artes no papel: Livros e revistas de artes plásticas no Brasil, Décadas de 80 e 90 . Mimeografado.

Rancière, J. (2005). A partilha do sensível: Estética e política. São Paulo: EXO/Editora 34.

Reinaldim, I. (2013). Em torno de uma ação de "A Moreninha": Algumas questões acerca do debate crítico na década de 1980. Arte \& Ensaios: Revista do PPGAV/EBA/UFRJ, Vol. 25, pp. 34-43.

Marcondes, G. (2014). O que representam os vernissages? Revista A! No. 1, 10. semestre de 2014, pp. 65-82.

Velthuis, O. (2005). Talking Prices: Symbolic meanings of prices on the market for contemporary art. Princeton/Oxford: Princeton University Press. 